\title{
Enucleation versus Anatomic Resection for Giant Hepatic Hemangioma: A Meta-Analysis
}

\author{
Yuhui Liu ${ }^{a}$ Xuyong Wei ${ }^{a}$ Kun Wang ${ }^{a}$ Qiaonan Shan ${ }^{a}$ Haojiang Daia \\ ${\text { Haiyang } X_{i e}{ }^{b} \text { Lin Zhou }}^{b} \quad$ Xiao Xu ${ }^{a, b}$ Shusen Zheng ${ }^{a, b}$ \\ a Division of Hepatobiliary and Pancreatic Surgery, Department of Surgery, First Affiliated \\ Hospital, Zhejiang University School of Medicine, and ${ }^{b}$ Key Laboratory of Combined \\ Multi-Organ Transplantation, Ministry of Public Health, Hangzhou, China
}

\section{Keywords}

Anatomic resection $\cdot$ Enucleation $\cdot$ Giant hepatic hemangioma $\cdot$ Meta-analysis

\begin{abstract}
Background: Hepatic hemangiomas are the most common benign liver tumors, and the management of giant hepatic hemangioma $(\mathrm{GHH})$ is still in controversial. The aim of this metaanalysis was to compare the postoperative outcomes of enucleation versus anatomic resection for GHH. Methods: PubMed, Embase, Web of Science, and the Cochrane Library were searched from January 1988 to December 2015 to identify studies comparing the outcomes of enucleation versus anatomic resection for $\mathrm{GHH}$. Finally, we performed this meta-analysis using the Review Manager 5.3 software, and the results were presented as risk ratio (RR) or mean difference (MD) with corresponding 95\% confidence interval (CI). The major limitation is that all data were derived from nonrandomized studies, and we cannot exclude potential selection bias. Results: Nine studies involving 1,185 patients were included. The results showed that there was a lower incidence of complications ( $R R=0.66,95 \%$ CI 0.52 to 0.84 , $\left.R^{2}=0 \%, p=0.0007\right) ;$ no incidents of death occurred among the 9 included trials. Blood loss $\left(\mathrm{MD}=-419.07 \mathrm{~mL}, 95 \% \mathrm{CI}-575.04\right.$ to $\left.-263.09, \mathrm{I}^{2}=83 \%, p<0.00001\right)$, duration of surgery $\left(\mathrm{MD}=-23.5 \mathrm{~min}, 95 \% \mathrm{CI}-45.28\right.$ to $\left.-1.74, R^{2}=0 \%, p=0.03\right)$, and length of hospital stay $\left(\mathrm{MD}=-1.59\right.$ days, $95 \% \mathrm{CI}-3.06$ to $-0.13, I^{2}=0 \%, p=0.03$ ) were much lower in the enucleation group. Conclusions: $\mathrm{GHH}$ can be removed safely by either enucleation or anatomic resection. Enucleation can preserve more hepatic parenchyma and reduce postoperative complications, which is why it should be the preferred surgical procedure for suitable lesions.
\end{abstract}




\section{Introduction}

Hepatic hemangiomas are the most common benign liver tumors, with the prevalence in autopsy series ranging from 3 to 20\% [1]. Most lesions are found in women (female:male ratio $=5: 1$ ) and are detected between the third and fifth decades [2]. The etiology of hepatic hemangioma is unclear; because of some cases of hepatic hemangioma running in families, it may be congenitally determined [3]. Histologically, hepatic hemangiomas are considered congenital vascular malformations instead of neoplastic processes [4].

Hepatic hemangiomas are usually discovered incidentally, and most of them are small ( $<1 \mathrm{~cm}$ in diameter), stable, and prone to expectant management when complications or symptoms are absent [5]. Giant hepatic hemangioma (GHH), which may cause a variety of symptoms or complications including abdominal pain, early satiety, nausea, vomiting, jaundice, fever, dyspnea, and spontaneous or traumatic rupture [6], is usually defined as hepatic hemangioma with a diameter $>4 \mathrm{~cm}$ [7]. What is more, Kasabach-Merritt syndrome, characterized by thrombocytopenia secondary to platelet sequestration and destruction within the hemangioma, may also occur [8].

Management by supervision through imaging methods every 6 months or annually is considered sufficient to assess development over time [3]. Indications for surgery include severe complications, progressive symptoms, rapid growth in size, a high risk of rupture, and a suspicion of malignancy. Although there is no agreement on the optimal management for GHH, surgery remains the most effective therapeutic modality for treatment [4].

Originally, resection of hemangiomas was performed by means of anatomic segmentectomy or lobectomy. In 1988, Alper et al. [9] first described enucleation, which is based on the macroscopic observation that hemangiomas are encapsulated by a dissection plane between the liver parenchyma and the hemangioma [10]. Most authors advocated enucleation because it is safer and quicker, with fewer overall complications and less blood loss [6, 11-13], while others concluded that results were similar between enucleation and anatomic resection $[14,15]$. Up to date, there has not been a corresponding meta-analysis to compare the 2 methods. Thus, we conducted this meta-analysis to summarize the existing evidence in order to compare the postoperative outcomes of enucleation versus resection for GHH.

\section{Methods}

This meta-analysis was performed according to the Preferred Reporting Items for Systematic Reviews and Meta-Analyses (PRISMA) guidelines [16]. All stages of the literature search, data extraction, and quality assessment were independently conducted by 2 authors (Y. Liu and K. Wang) and validated by a third one (X. Wei). The study protocol was approved by the ethics committee of Zhejiang University School of Medicine and complied with the Declaration of Helsinki.

\section{Literature Search}

A systematic search of the literature using PubMed, Embase, Web of Science, and the Cochrane Library databases was carried out to identify studies using a combination of the search terms "hepatic or liver," "hemangioma," and "enucleation." All of the studies had been published from January 1988 to December 2015. In addition, the reference lists of relevant studies were searched manually.

Inclusion and Exclusion Criteria

The inclusion criteria were determined by 2 reviewers (Y. Liu and $\mathrm{K}$. Wang), and the studies had to meet the following major criteria: (1) proven diagnosis of hepatic hemangioma in patients; (2) studies comparing outcomes of enucleation versus anatomic resection for patients with hepatic hemangioma; (3) provide at least 1 relevant outcome on complications, blood loss, surgical time, or hospital stay. Duplicate publications, publications not in English or Chinese, reviews, studies providing insufficient raw data, and descriptive studies without control subjects were excluded. 
Fig. 1. Flow diagram of the study

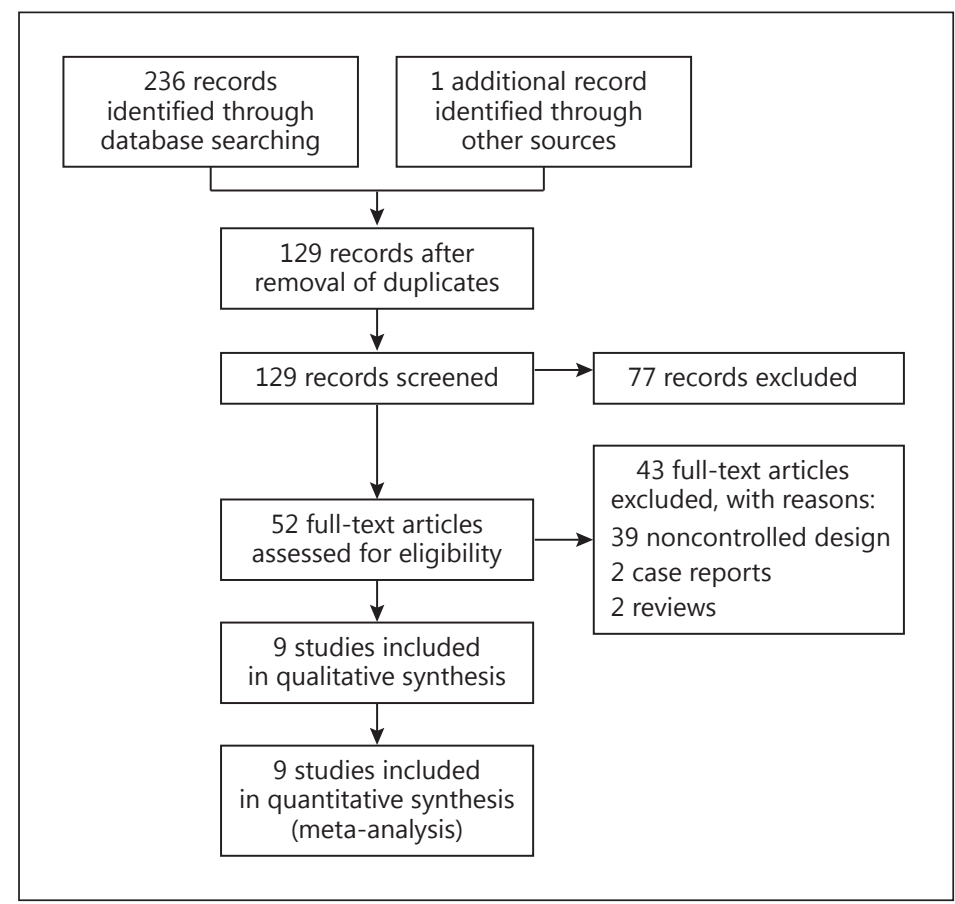
selection procedure.

Data Extraction and Quality Assessment

The primary goal of this meta-analysis was to compare the outcomes of enucleation versus anatomic resection for $\mathrm{GHH}$, so at least one of the following outcomes had to be included: complications, blood loss, surgical time, or hospital stay. In addition, basic data were extracted from each study as follows: first author, study design, sample size, and patient characteristics.

We used the validated Newcastle-Ottawa Quality Assessment Scale for cohort and case-control studies to perform quality assessment in each of the included studies. The scores ranged from 0 to 9 , with 0 and 9 being regarded as lowest and highest quality, respectively [17].

\section{Statistical Analysis}

Statistical analysis was performed using the Review Manager 5.3 software (The Cochrane Collaboration, Oxford, UK). Considering the clinical heterogeneity and the methodological variations between studies, the random effects model as described by DerSimonian and Laird [18] was used to control heterogeneity. For dichotomous outcomes, risk ratio (RR) and 95\% confidence interval (CI) calculated by a Mantel-Haenszel model were used. For continuous outcomes, the mean difference (MD) was calculated; when essential data were unavailable, the median and range were used to estimate the mean and standard deviation (SD) following the method described by Hozo et al. [19].

Statistical heterogeneity was assessed using the $I$ [2] statistic [20], with $I^{2}$ values of 25, 50, and 75\% being defined as low, moderate, and high levels of heterogeneity, respectively. Heterogeneity was rechecked using the $\chi^{2}$-based $\mathrm{Q}$ statistic, for which a $p$ value $<0.05$ indicated significant heterogeneity. If there was substantial heterogeneity, we conducted subgroup analysis to explore the potential sources. Sensitivity analysis was also performed by excluding the studies one by one to detect the stability of our results. In addition, potential publication bias was evaluated with the Begg and Egger tests.

\section{Results}

\section{Selection and Characteristics of Studies}

Studies assessing the efficacy and safety of enucleation compared with anatomic resection for the management of GHH were included. Figure 1 shows the flow diagram of the study 
Table 1. Characteristics of the included studies

\begin{tabular}{|c|c|c|c|c|c|c|c|}
\hline $\begin{array}{l}\text { Reference } \\
\text { (first author) }\end{array}$ & $\begin{array}{l}\text { Country or } \\
\text { region/city }\end{array}$ & $\begin{array}{l}\text { Study } \\
\text { period }\end{array}$ & $\begin{array}{l}\text { Sample size } \\
(\mathrm{M} / \mathrm{F})\end{array}$ & $\begin{array}{l}\text { Enucleation, } \\
n\end{array}$ & $\begin{array}{l}\text { Resection, } \\
n\end{array}$ & Study design & $\begin{array}{l}\text { NOS } \\
\text { scores }\end{array}$ \\
\hline $\begin{array}{l}\text { Gedaly [6], } \\
1999\end{array}$ & USA/Boston & 1987-1997 & $28(4 / 24)$ & 23 & 5 & retrospective & $6 / 9$ \\
\hline $\begin{array}{l}\text { Hamaloglu [11], } \\
2005\end{array}$ & Turkey/Ankara & 1989-2002 & $22(1 / 21)$ & 10 & 12 & retrospective & $8 / 9$ \\
\hline $\begin{array}{l}\text { Singh [12], } \\
2007\end{array}$ & India/New Delhi & 1987-2003 & $21(8 / 13)$ & 9 & 12 & retrospective & $7 / 9$ \\
\hline Qiu [13], 2015 & China/Chongqing & $2004-2013$ & $730(429 / 301)$ & 386 & 344 & prospective & $8 / 9$ \\
\hline $\begin{array}{l}\text { Giuliante [14], } \\
2011\end{array}$ & Italy/Rome & $1992-2008$ & 40 (NR) & 12 & 28 & prospective & $7 / 9$ \\
\hline $\begin{array}{l}\text { Zhang [15], } \\
2015\end{array}$ & China/Wuhan & 2007-2014 & $86(27 / 59)$ & 46 & 40 & retrospective & $8 / 9$ \\
\hline $\begin{array}{l}\text { Lerner [21], } \\
2004\end{array}$ & USA/Los Angeles & $1990-2003$ & $52(6 / 46)$ & 27 & 25 & retrospective & $7 / 9$ \\
\hline Xiao [22], 2015 & China/Beijing & $2006-2014$ & $145(31 / 114)$ & 81 & 64 & retrospective & 7/9 \\
\hline Но [23], 2012 & Taiwan/Taoyuan & $2000-2010$ & $61(16 / 45)$ & 25 & 36 & retrospective & $7 / 9$ \\
\hline
\end{tabular}

NOS, Newcastle-Ottawa Quality Assessment Scale; NR, not reported.

Table 2. Hemangioma number and size between the 2 groups

\begin{tabular}{|c|c|c|c|c|c|c|}
\hline \multirow{2}{*}{$\begin{array}{l}\text { Reference } \\
\text { (first author) }\end{array}$} & \multicolumn{3}{|c|}{ Hemangioma number } & \multicolumn{3}{|l|}{ Hemangioma size } \\
\hline & $\begin{array}{l}\text { enucleation } \\
(\mathrm{SH}), n(\%)\end{array}$ & $\begin{array}{l}\text { resection } \\
(\mathrm{SH}), n(\%)\end{array}$ & $\begin{array}{l}p \\
\text { value }\end{array}$ & $\begin{array}{l}\text { enucleation, } \\
\mathrm{cm}\end{array}$ & $\begin{array}{l}\text { resection, } \\
\mathrm{cm}\end{array}$ & $\begin{array}{l}p \\
\text { value }\end{array}$ \\
\hline Gedaly [6], 1999 & NR & NR & NR & $6.0 \pm 3.7$ & $8.6 \pm 5.4$ & $>0.05$ \\
\hline Hamaloglu [11], 2005 & NR & NR & NR & 7.75 (range 1.40 ) & 8.10 (range 23) & 0.92 \\
\hline Singh [12], 2007 & NR & NR & NR & $8.9(5-15)$ & $10(4-25)$ & 0.858 \\
\hline Qiu [13], 2015 & $304(78.8 \%)$ & $276(80.2 \%)$ & 0.541 & $9.8(1.5-15.7)$ & $10.6(1.8-14.4)$ & 0.752 \\
\hline Giuliante [14], 2011 & NR & NR & NR & $12.3(3.5-46)$ & $11.8(2.6-29)$ & $>0.05$ \\
\hline Zhang [15], 2015 (R) & $1(1-4)$ & $1(1-2)$ & 0.902 & $13.0 \pm 3.3$ & $17.5 \pm 8.1$ & 0.063 \\
\hline Zhang [15], 2015 (L) & $2(1-3)$ & $1(1-3)$ & 0.034 & $14.8 \pm 5.4$ & $12.8 \pm 3.8$ & 0.281 \\
\hline Lerner [21], 2004 & $21(78 \%)$ & $24(96 \%)$ & 0.10 & $10.1 \pm 5.3$ & $11.6 \pm 4.3$ & 0.28 \\
\hline Xiao [22], 2015 & $47(58 \%)$ & $28(47.3 \%)$ & 0.123 & $12.0(11.0-14.0)$ & $15.5(11.8-20.5)$ & $<0.01$ \\
\hline Но [23], 2012 & $20(80 \%)$ & $24(66.7 \%)$ & 0.593 & NR & NR & NR \\
\hline
\end{tabular}

L, left liver group; NR, not reported; R, right liver group; SH, solitary hemangioma.

selection procedure. In total, 237 articles were originally screened out, including 69 from PubMed, 68 from Web of Science, 99 from Embase, and 1 from other sources. After careful screening, 9 studies met the selection criteria in the meta-analysis [6, 11-15, 21-23]. One of the 9 included trials [15] consisted of 2 subgroups (right liver group and left liver group), so 
Fig. 2. Funnel plot based on postoperative complications. RR, risk ratio.

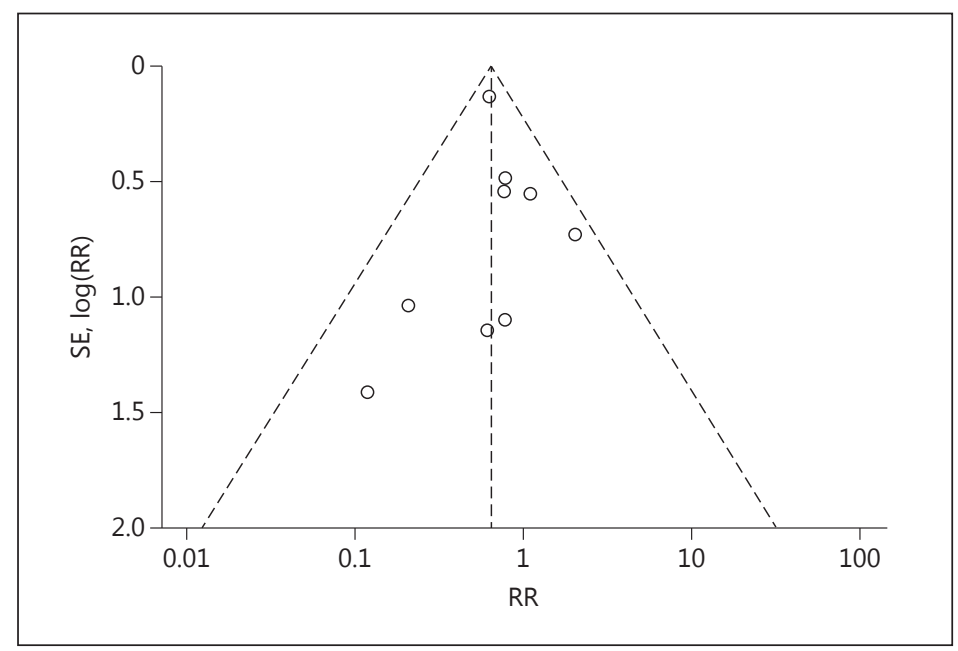

we analyzed the data extracted from the 2 subgroups separately. There were in total 2 prospective observational clinical studies $[13,14]$ and 7 retrospective studies, including 1,185 patients: 619 in the enucleation group and 566 in the resection group. Three of the studies had been conducted in China, 2 in the USA, and the remaining 4 in Italy, Turkey, Taiwan, and India, respectively. The characteristics of each trial are shown in Table 1. Five studies reported hemangioma number $[13,15,21-23]$ and 8 studies reported hemangioma size between the 2 groups $[6,11-15,21,22]$. In most cases, there were no statistical differences between the 2 groups. Details are shown in Table 2.

\section{Quality Assessment and Publication Bias}

All of the 9 included studies were nonrandomized controlled trials, including 7 retrospective and 2 prospective observational clinical trials. The main characteristics and the quality assessment results of the 9 included studies are illustrated in Table 1.

As shown in Figure 2, the funnel plot based on postoperative complications was broadly symmetrical, indicating minimal publication bias; the Begg and Egger tests were also performed to provide further statistical evidence ( $p=0.348$ and $p=0.882$, respectively). Publication bias based on other outcomes was not assessed because of the limited number of included studies.

\section{Postoperative Complications and Mortality}

Postoperative complications were reported in all of the 9 studies [6, 11-15, 21-23], but the data from 1 trial were unavailable [6]. There was no heterogeneity among the included studies $\left(\chi^{2}=6.29, \mathrm{df}=8, p=0.62, I^{2}=0 \%\right)$. The pooled data showed that the enucleation group had a significantly lower incidence of postoperative complications when compared with the anatomic resection group ( $\mathrm{RR}=0.66,95 \% \mathrm{CI} 0.52$ to $0.84, p=0.0007$; Fig. 3). A particularly mentionable fact is that all of the 9 included trials reported that surgery-related mortality was 0 in both the enucleation and the anatomic resection group.

\section{Blood Loss}

Six trials reported this outcome measure $[6,11-13,15,22]$, but data from only 4 studies were available for meta-analysis $[6,12,13,22]$. Gedaly et al. [6] reported this outcome as mean and SD, while in the other 3 studies, median and range were used to estimate mean and 


\section{Tumors}

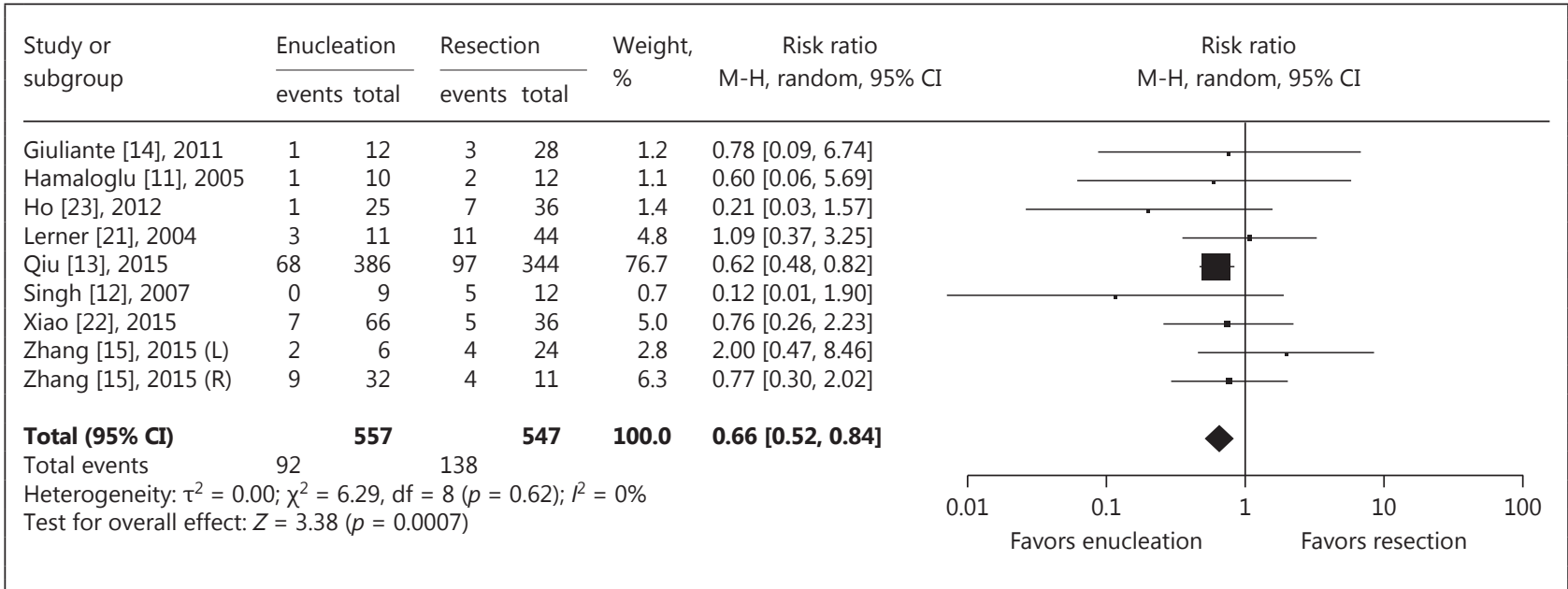

Fig. 3. Forest plot of postoperative complications. CI, confidence interval; L, left liver group; M-H, MantelHaenszel; R, right liver group.

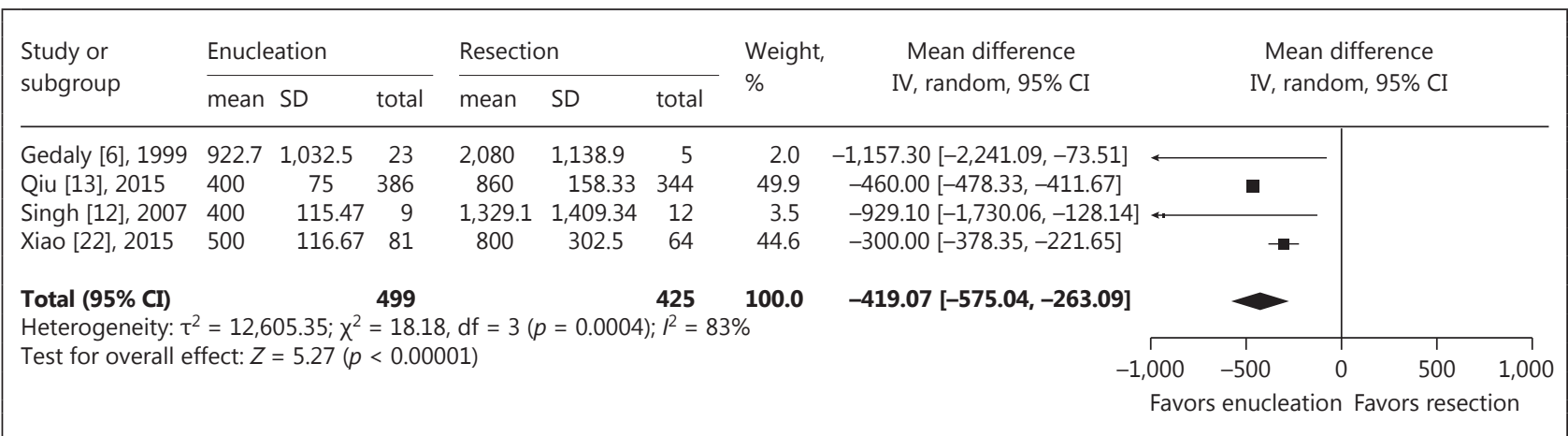

Fig. 4. Forest plot of intraoperative blood loss. CI, confidence interval; IV, inverse variance; SD, standard deviation.

SD $[12,13,22]$. Meta-analysis demonstrated that blood loss was significantly lower in the enucleation group (MD $=-419.07 \mathrm{~mL}, 95 \% \mathrm{CI}-575.04$ to $-263.09, p<0.00001$ ), with significant heterogeneity among studies $\left(I^{2}=83 \%, p=0.0004 ;\right.$ Fig. 4$)$.

\section{Surgical Time}

Seven studies were included $[6,12-15,21,22]$, and the data extracted from 4 studies were estimated from median and range, thus we divided the data into 2 groups and performed subgroup analyses (Fig. 5). In the initial data group, heterogeneity among the studies was no remarkable $\left(I^{2}=0 \%, p=0.47\right)$; surgical time was significantly shorter for patients receiving enucleation than for those receiving anatomic resection (MD $=-23.51 \mathrm{~min}, 95 \% \mathrm{CI}-45.28$ to $-1.74, p=0.03$ ). In the estimated data group, the pooled data showed similar results (MD = $-72.93 \mathrm{~min}, 95 \% \mathrm{CI}-93.21$ to $-52.64, p<0.00001$ ), but heterogeneity among studies was significant $\left(I^{2}=84 \%, p=0.0003\right.$; Fig. 5$)$. 


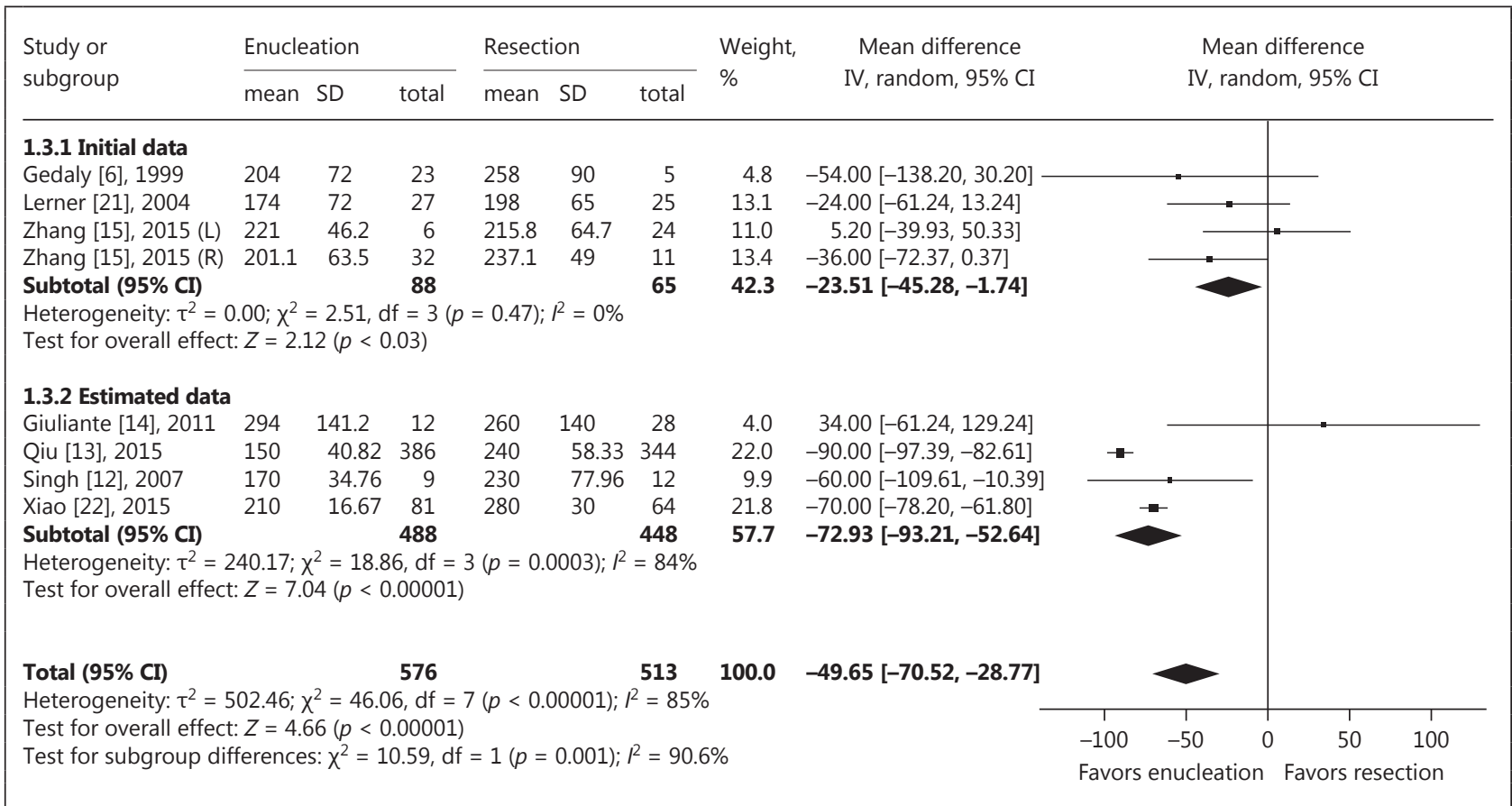

Fig. 5. Forest plot of surgical time. CI, confidence interval; IV, inverse variance; L, left liver group; R, right liver group; SD, standard deviation.

\section{Hospital Stay}

Five studies $[6,12,13,21,22]$ were included. In the initial data group, there was no heterogeneity among the included studies $\left(\chi^{2}=0.15, \mathrm{df}=1, p=0.70, I^{2}=0 \%\right)$. Hospital stay was 1.59 days shorter for patients receiving enucleation than for those receiving anatomic resection (MD $=-1.59$ days, $95 \% \mathrm{CI}-3.06$ to $-0.13, p=0.03$ ). In the estimated data group, the pooled data showed similar results (MD $=-4.02$ days, $95 \% \mathrm{CI}-5.82$ to $-2.22, p<0.0001$ ), with significant heterogeneity among studies $\left(I^{2}=97 \%, p<0.00001\right.$; Fig. 6).

\section{Discussion}

The management of GHH varies from observation to a variety of nonsurgical and surgical interventions [24]. For most cases, management by supervision through imaging methods every 6 months or annually is considered sufficient [3]. However, GHH may also become symptomatic by pressure on the liver or adjacent organs, the most common symptoms being abdominal pain or distention [10]. Surgical treatment of the GHH, which includes enucleation, liver resection, and liver transplantation, is more radical than the other modalities and also allows histologic examination of the specimen [9].

The indications for surgical treatment include severe symptoms, rapid growth in size, a suspicion of malignancy, and a high risk of rupture. In 1988, Alper et al. [9] first described enucleation, as there was a definite and easily separable cleavage plane; this procedure was mainly achieved by blunt dissection of the vessels entering or leaving the hepatic hemangioma, thus preserving more liver parenchyma. The choice of resection or enucleation of GHH is mainly dependent on the location, size and number of lesions, as well as preference and technical skill of the surgeon $[11,21]$. 


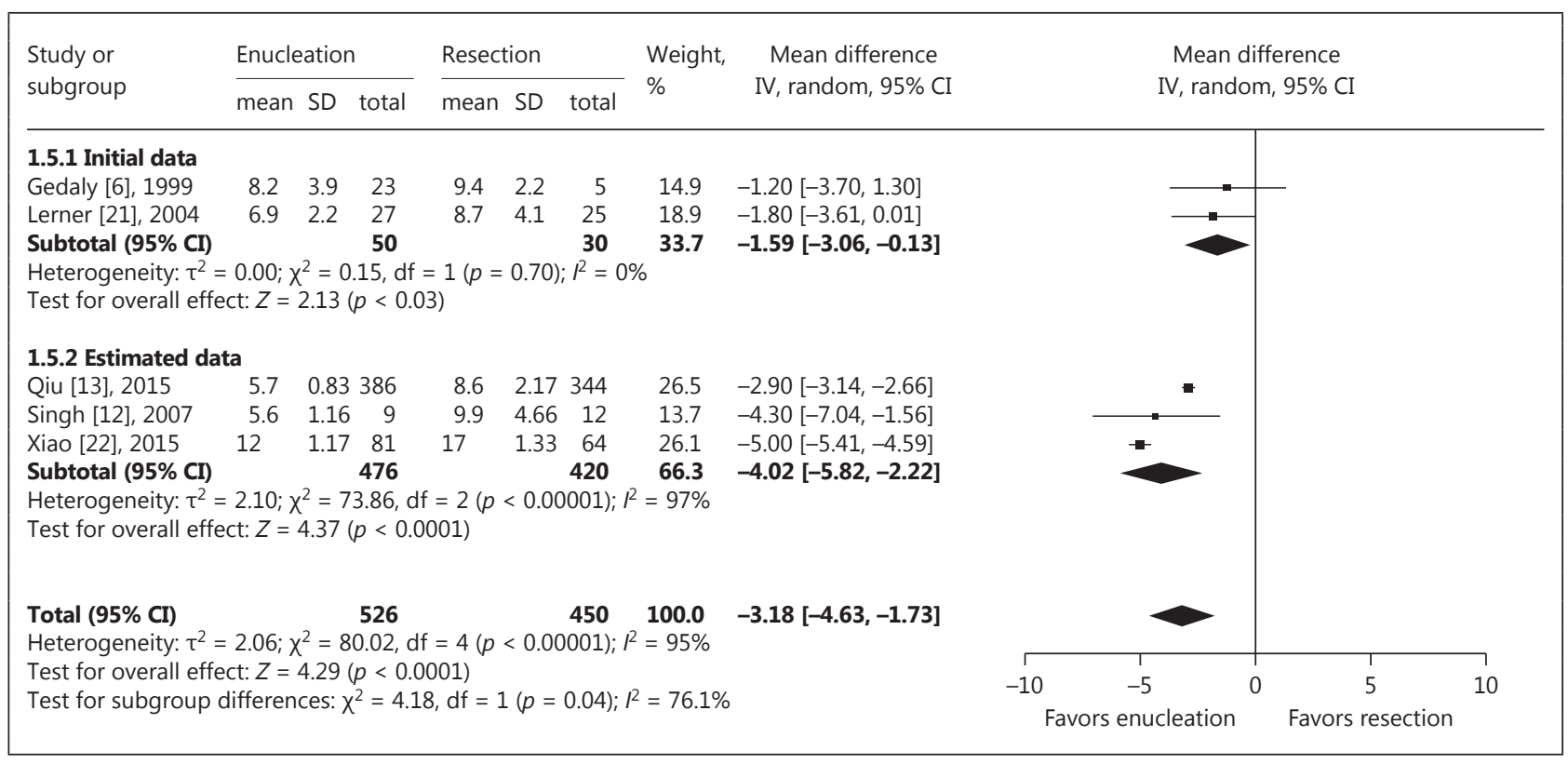

Fig. 6. Forest plot of hospital stay. CI, confidence interval; IV, inverse variance; SD, standard deviation.

Most authors advocated enucleation rather than anatomic liver resection, although 2 studies reported that results were similar between enucleation and anatomic resection: Giuliante et al. [14] pointed out that the risk of blood loss was related more to the large size of the hemangioma than to the type of surgery, while Zhang et al. [15] concluded that adjacency to major vascular structures was an independent predictive factor.

As far as we know, this is the first meta-analysis summarizing current evidence comparing the outcomes of enucleation versus those of anatomic resection for GHH. In this meta-analysis of 1,185 patients, pooled results demonstrated that the risk of complications was significantly lower in the enucleation group, with limited heterogeneity. A particularly mentionable fact is that all of the 9 included studies reported that there was no surgery-related death in either the enucleation or the anatomic resection group. At the same time, blood loss, hospital stay, and surgical time were significantly lower in the enucleation group. In summary, the following reasons may contribute to this result: (1) Enucleation is simpler than resection and can reduce operative blood loss, as there is a dissection plane between the liver parenchyma and the hemangioma [25]. (2) Enucleation carries a low risk of biliary leakage, perhaps because there is a clear border between the hemangioma and the normal liver parenchyma, and avoids unnecessary injury of bile ducts [13]. (3) Enucleation avoids unnecessary loss of healthy liver parenchyma [26].

In general, comparisons between enucleation and liver resection demonstrate that enucleation is associated with lower morbidity and may become a preferable choice for surgeons. Indications for enucleation include: (1) the fibrous rim between the hemangioma and the surrounding liver parenchyma is easily recognizable; (2) the location of the hemangioma is very peripheral or right-sided; (3) intent to preserve more healthy liver parenchyma [14]. In the early 21st century, the progress of liver surgery is characterized by precision, minimal invasiveness, and effectiveness [27]. Enucleation meets the requirement of precise surgery, which can be adopted by more and more surgeons. 
A major limitation is that all data were derived from nonrandomized controlled trials, and we cannot exclude potential information bias, selection bias, and confounding bias. Only 1 study pointed out that patients treated with transhepatic arterial embolization followed by hepatic resection were excluded [13], while essential information in other trials was absent. What is more, the Pringle maneuver was used selectively in some cases; that is also one of the most important reasons that we cannot perform randomized controlled trials. In some trials, median and range were used to estimate mean and SD following the method described by Hozo et al. [19], although we performed subgroup analysis to explore potential heterogeneity.

In conclusion, GHH can be removed safely by either enucleation or anatomic resection. Enucleation can preserve more normal hepatic parenchyma and reduce postoperative complications, which is why it should be the preferred surgical procedure for suitable lesions.

\section{Acknowledgments}

This work was supported by grants from the Chang Jiang Scholars Program (No. T2014146), 151 Talents Project of Zhejiang Province (No. 12-1-058), and Transformation Projects of Appropriate Technical Achievements in Primary Health Care of Zhejiang Province (No. 2013T301-15).

\section{Disclosure Statement}

The authors declare no conflict of interest.

\section{References}

1 Choi BY, Nguyen MH: The diagnosis and management of benign hepatic tumors. J Clin Gastroenterol 2005;39: 401-412.

2 Duxbury MS, Garden OJ: Giant haemangioma of the liver: observation or resection? Dig Surg 2010;27:7-11.

3 Bajenaru N, Balaban V, Savulescu F, Campeanu I, Patrascu T: Hepatic hemangioma - review. J Med Life 2015; 8(spec issue):4-11.

4 Yoon SS, Charny CK, Fong Y, Jarnagin WR, Schwartz LH, Blumgart LH, DeMatteo RP: Diagnosis, management, and outcomes of 115 patients with hepatic hemangioma. J Am Coll Surg 2003;197:392-402.

5 Schnelldorfer T, Ware AL, Smoot R, Schleck CD, Harmsen WS, Nagorney DM: Management of giant hemangioma of the liver: resection versus observation. J Am Coll Surg 2010;211:724-730.

6 Gedaly R, Pomposelli JJ, Pomfret EA, Lewis WD, Jenkins RL: Cavernous hemangioma of the liver: anatomic resection vs. enucleation. Arch Surg 1999;134:407-411.

7 Di Carlo I, Koshy R, Al Mudares S, Ardiri A, Bertino G, Toro A: Giant cavernous liver hemangiomas: is it the time to change the size categories? Hepatobiliary Pancreat Dis Int 2016;15:21-29.

8 Hall GW: Kasabach-Merritt syndrome: pathogenesis and management. Br J Haematol 2001;112:851-862.

9 Alper A, Ariogul O, Emre A, Uras A, Okten A: Treatment of liver hemangiomas by enucleation. Arch Surg 1988; 123:660-661.

10 Demiryürek H, Alabaz O, Ağdemir D, Sungur I, Erkoçak EU, Akinoğlu A, Alparslan A, Zorludemir S: Symptomatic giant cavernous haemangioma of the liver: is enucleation a safe method? A single institution report. HPB Surg 1997; 10:299-304.

11 Hamaloglu E, Altun H, Ozdemir A, Ozenc A: Giant liver hemangioma: therapy by enucleation or liver resection. World J Surg 2005;29:890-893.

12 Singh RK, Kapoor S, Sahni P, Chattopadhyay TK: Giant haemangioma of the liver: is enucleation better than resection? Ann R Coll Surg Engl 2007;89:490-493.

13 Qiu J, Chen S, Wu H: Quality of life can be improved by surgical management of giant hepatic haemangioma with enucleation as the preferred option. HPB (Oxford) 2015;17:490-494.

14 Giuliante F, Ardito F, Vellone M, Giordano M, Ranucci G, Piccoli M, Giovannini I, Chiarla C, Nuzzo G: Reappraisal of surgical indications and approach for liver hemangioma: single-center experience on 74 patients. Am J Surg 2011;201:741-748.

15 Zhang W, Huang ZY, Ke CS, Wu C, Zhang ZW, Zhang BX, Chen YF, Zhang WG, Zhu P, Chen XP: Surgical treatment of giant liver hemangioma larger than $10 \mathrm{~cm}$ : a single center's experience with 86 patients. Medicine (Baltimore) 2015;94:e1420. 
16 Moher D, Liberati A, Tetzlaff J, Altman DG; PRISMA Group: Preferred reporting items for systematic reviews and meta-analyses: the PRISMA statement. Open Med 2009;3:e123-e130.

17 Reeves BC, Higgins JP, Ramsay C, Shea B, Tugwell P, Wells GA: An introduction to methodological issues when including non-randomised studies in systematic reviews on the effects of interventions. Res Synth Methods 2013;4:1-11.

18 DerSimonian R, Laird N: Meta-analysis in clinical trials. Control Clin Trials 1986;7:177-188.

19 Hozo SP, Djulbegovic B, Hozo I: Estimating the mean and variance from the median, range, and the size of a sample. BMC Med Res Methodol 2005;5:13.

20 Higgins JP, Thompson SG: Quantifying heterogeneity in a meta-analysis. Stat Med 2002;21:1539-1558.

21 Lerner SM, Hiatt JR, Salamandra J, Chen PW, Farmer DG, Ghobrial RM, Busuttil RW: Giant cavernous liver hemangiomas: effect of operative approach on outcome. Arch Surg 2004;139:818-821.

22 Xiao N, Yu Q, Duan W, Dong J: Surgical management of giant hemangioma of the liver: enucleation versus hepatectomy. Chin J Gen Surg 2015;30:436-439.

23 Ho HY, Wu TH, Yu MC, Lee WC, Chao TC, Chen MF: Surgical management of giant hepatic hemangiomas: complications and review of the literature. Chang Gung Med J 2012;35:70-78.

24 Hoekstra LT, Bieze M, Erdogan D, Roelofs JJ, Beuers UH, van Gulik TM: Management of giant liver hemangiomas: an update. Expert Rev Gastroenterol Hepatol 2013;7:263-268.

25 Zimmermann A, Baer HU: Fibrous tumor-liver interface in large hepatic neoplasms: its significance for tumor resection and enucleation. Liver Transpl Surg 1996;2:192-199.

26 Ozden I, Emre A, Alper A, Tunaci M, Acarli K, Bilge O, Tekant Y, Ariogul O: Long-term results of surgery for liver hemangiomas. Arch Surg 2000;135:978-981.

27 Dong J: Precision liver surgery. Chin J Dig Surg 2014;13:405-411. 